\title{
Crecimiento urbano y cambios del uso/ cobertura del suelo en las ciudades de Necochea y Quequén, Buenos Aires, Argentina $^{1}$
}

\author{
Alejandra Merlotto ${ }^{2}$, María Cintia Piccolo 3 y Germán Ricardo Bértola ${ }^{4}$
}

\begin{abstract}
RESUMEN
La urbanización es un proceso territorial y socioeconómico que induce una transformación radical del uso/cobertura del suelo y constituye el proceso que mayores cambios produce en el medio ambiente y, por lo tanto, está íntimamente ligado al incremento de los problemas y riesgos ambientales. Mediante fotografías aéreas e imágenes satelitales se evaluó la dinámica del crecimiento urbano y los cambios del uso/cobertura del suelo del área urbana costera del Partido de Necochea (Argentina). Desde el año 1967 al 2004, el espacio ocupado por el uso del suelo urbano se incrementó de 21,95 a 28,44\% del área total estudiada, en detrimento del uso no urbano. El crecimiento de la población acompañó y superó significativamente el ritmo de expansión urbana, evidenciando que el proceso de densificación de la ocupación es notablemente superior al del crecimiento de la mancha urbana.
\end{abstract}

Palabras clave: Crecimiento urbano, uso/cobertura del suelo, Necochea, Quequén

\begin{abstract}
Urbanization is a territorial and socioeconomic process that induces a radical transformation of land/use cover. It produces great changes in the environment and therefore, is the principal cause of environmental problems and risks. Based on aerial photographs and satellital images, urban growth dynamics and land/use cover change were evaluated at the coastal urban area of Necochea municipality (Argentina). Between 1967 and 2004, urban land/cover use increased from 21,95 to $28,44 \%$ while non urban land/cover use descended. Population growth excedeed urban expansion rate, estimating that the densification of urban occupation is notably higher than the urban sprawl growth.
\end{abstract}

Key words: urban growth, land use/cover change, Necochea, Quequén.

1 Proyecto financiado por CONICET-UNMdP-UNS. Artículo recibido el 5 de septiembre de 2011, aceptado el 20 de mayo de 2012 y corregido el 29 de mayo de 2012.

2 Consejo Nacional de Investigaciones Científicas y Técnicas (CONICET). Instituto de Geología de Costas y del Cuaternario, Facultad de Ciencias Exactas y Naturales, Universidad Nacional de Mar del Plata (Argentina). E-mail: amerlott@mdp.edu.ar
3 Consejo Nacional de Investigaciones Científicas y Técnicas (CONICET). Departamento de Geografía y Turismo, Universidad Nacional del Sur (Argentina). E-mail: ofpiccol@criba.edu.ar

4 Consejo Nacional de Investigaciones Científicas y Técnicas (CONICET). Instituto de Geología de Costas y del Cuaternario, Facultad de Ciencias Exactas y Naturales, Universidad Nacional de Mar del Plata (Argentina). E-mail: gbertola@mdp.edu.ar 
La urbanización es un proceso territorial y socioeconómico que induce una transformación radical de la cobertura y del uso del suelo (Weber y Puissant, 2003), el cual se encontraba ocupado en general por paisajes naturales o estaba dedicado a actividades agropecuarias. Constituye el proceso que mayores cambios produce en el medio ambiente (Pascual Aguilar et al., 2006; Catalán et al., 2008; Batisani \& Yarnal, 2009) y en el funcionamiento de los ecosistemas y, por lo tanto, está íntimamente ligado al incremento de los problemas ambientales y de los riesgos a fenómenos naturales (López et al., 2001). La urbanización acelerada cambia la estructura de las ciudades y afecta su climatología y la de su área circundante (Tang et al., 2008).

En la región pampeana argentina, desde mediados de la década de los años 40 , tierras de gran aptitud agrícola han sido transformadas a usos urbanos e industriales debido a la expansión de las ciudades, principalmente del área metropolitana de la ciudad de Buenos Aires (Morello et al., 2000). Asimismo, la urbanización no se ha presentado con la misma intensidad en todos los países. La población urbana mundial alcanzó el $47 \%$ en el año 2000 (Bolay y Ravinovich, 2004), mientras que en Argentina en el año 2001 la población urbana total era del 89,3\% (INDEC, 2005). Sin embargo, la falta de planificación, en mayor o menor medida, caracteriza la expansión de la mayor parte de las ciudades del mundo. El constante crecimiento urbano y demográfico de las grandes aglomeraciones con ausencia de una planificación integral ha generado, además, condiciones deficientes de habitabilidad que afectan la calidad de vida de sus habitantes.

Desde el desarrollo de las grandes civilizaciones, el hombre se ha asentado preferentemente en áreas fluviales y costeras debido a la gran disponibilidad de recursos naturales $y$, por lo tanto, del aprovechamiento económico que podía efectuarse en las mismas. En el año 1995, el 39\% de la población mundial vivía a una distancia menor a $100 \mathrm{~km}$ de la costa y diversos estudios sugieren que la población costera aumenta a un ritmo mayor que la de otras regiones (Crawford, 2007). Las áreas costeras se ven afectadas por consiguiente por el constante crecimiento de las ciudades asentadas sobre ellas y por el desarrollo de las actividades del hombre, ya sean productivas, industriales, turísticas o comerciales. Además de desarrollarse problemas ambientales propios de la mayor parte de los centros urbanos, en las áreas costeras se manifiestan otros problemas como la contaminación por descarga de aguas residuales (Ortiz Lozano et al., 2005), alteraciones en los nutrientes y eutrofización en estuarios y costas abiertas (Dennison, 2008), efectos negativos sobre la biodiversidad y hábitats acuáticos (Gillies et al., 2003; Xie et al., 2010), entre otros. En las costas de la provincia de Buenos Aires, la erosión costera es uno de los problemas ambientales más importantes y es causada por la combinación de factores tanto de origen natural como antrópico (Merlotto y Bértola, 2009). Los procesos erosivos pueden generar importantes consecuencias socioeconómicas para la población residente de áreas costeras. Por ejemplo, en el este de la provincia de Buenos Aires, en el Balneario Parque Mar Chiquita, se perdieron numerosas viviendas y gran cantidad de lotes por el avance del mar a lo largo de la segunda mitad del siglo XX (Merlotto y Bértola, 2007).

Los estudios más frecuentes que contemplan la evolución del paisaje urbano sobre el medio natural son los relacionados a la pérdida de suelo rural destinado a la agricultura o a bosques en el periurbano de las grandes urbes del mundo, donde los usos rurales desaparecen frente a la expansión sin control de la ciudad (Morello et al., 2000; López et al., 2001; Fujihara et al., 2005; Hara et al., 2005; Rayburn y Schulte, 2009). En menor medida se evalúa el crecimiento de las ciudades costeras (Weber y Puisant, 2003; Pascual Aguilar et al., 2006; Valera Lozano et al., 2007; Catalán et al., 2008) y los estudios sobre su influencia en los fenómenos erosivos son escasos. En la provincia de Buenos Aires, Juárez e Isla (1999) y Juárez et al. (2001) evaluaron la evolución urbana de sectores de los partidos de Villa Gesell y General Pueyrredón, y Merlotto y Bértola (2008) en el Balneario Parque Mar Chiquita. Dichos estudios estimaron que la fijación del campo de médanos para su urbanización y forestación, generó cambios en el ambiente y desequilibrios sedimentarios que influyeron negativamente en la dinámica de las playas. 
El crecimiento urbano y los cambios del uso/cobertura del suelo constituyen procesos que forman parte del desarrollo urbano (Bhatta et al., 2010). El estudio de estos temas es fundamental para la elaboración de propuestas de ordenamiento territorial y planeamiento municipal debido a sus aportes en relación a la forma en que se materializa el crecimiento físico de la ciudad, la dinámica de la expansión urbana y la desaparición del suelo rural, el ritmo de la ocupación, entre otros (Ward et al., 2000; Nasarre Vázquez y Badia Perpinyá, 2006; Valera Lozano et al., 2007). Este conocimiento es utilizado además para predecir la expansión de las ciudades con el fin de prever las futuras demandas (infraestructura, servicios) de la población que se asentará en esas tierras y planificar nuevos asentamientos (López et al., 2001; Hathout, 2002).

Para reconstruir la dinámica del crecimiento de las ciudades y evaluar los cambios en el usos/cobertura del suelo, está ampliamente difundido el uso de fotografías aéreas (Hathout, 2002; Azócar et al., 2003; Herold et al., 2003; Nasarre Vázquez y Badia Perpinyá, 2006; Pascual Aguilar et al., 2006; Valera Lozano et al., 2007; Merlotto y Bértola, 2008; Azócar et al., 2010). Otros trabajos que evalúan específicamente el ritmo de expansión urbana han utilizado imágenes satelitales de distinta resolución espacial como las adquiridas por los satélites LANDSAT o SPOT (Ward et al., 2000; Herrera, 2001; Weber y Puissant, 2003; Martinuzzi et al., 2007). A pesar que los nuevos sensores (IKONOS, QuickBird, OrbView) han proporcionado nuevas aplicaciones (Blaschke, 2010), las fotografías aéreas son las fuentes más utilizadas ya que constituyen una opción más accesible debido al alto costo de las imágenes satelitales de alta resolución, las cuales, además, son inexistentes para estudios de fechas históricas (Pascual Aguilar et al., 2006).

La urbanización del sector costero del Partido de Necochea ha producido una intensa y variada utilización de los recursos (playas, médanos, río) en diversos usos (actividades agropecuarias, agroindustrias, navegación, comercio, turismo), lo que ha llevado a interferencias con los procesos naturales (transporte de sedimentos, dinámica estuarial, migración de médanos, dinámica de playas).
El área sujeta a estudio corresponde al área urbana y al área complementaria del aglomerado urbano conformado por las ciudades de Necochea y Quequén (Figura $N^{0} 1$ ), de acuerdo con la zonificación vigente en la Ordenanza 2005/81 del Partido de Necochea. Las mismas se emplazan a ambos lados del río Quequén Grande, en cuya desembocadura se asienta el puerto Quequén. La instalación del puerto y el crecimiento de las ciudades han alterado el paisaje y su dinámica natural, facilitando la ocurrencia de diversos problemas ambientales. Entre ellos, inundaciones debidas a desbordes del río Quequén Grande y tormentas, contaminación costera e hídrica (superficial y subterránea) (FAUD/ UNMdP, 1997) ocasionada por el vertido de efluentes cloacales y líquidos industriales, emanaciones, basurales y erosión costera. Asimismo, las modificaciones antropogénicas producidas en la boca del estuario del río han inducido fuertes cambios en los patrones de circulación del mismo (Perillo et al., 2005). Es por ello que conocer la dinámica urbana del área de estudio constituye un aspecto esencial y prioritario para la planificación y ordenamiento territorial y para la evaluación del riesgo a fenómenos naturales. El objetivo del presente trabajo fue evaluar la dinámica de la expansión urbana y los cambios en los usos/cobertura del suelo en el área urbana de la costa del Partido de Necochea. Asimismo, se estudiaron los procesos socioeconómicos y el crecimiento de la población con el fin de entrever las causas que han guiado el desarrollo urbano del área de estudio.

\section{Método de trabajo}

Se utilizó el plano catastral digital del ejido urbano del aglomerado NecocheaQuequén, proporcionado por la Municipalidad del Partido de Necochea. Empleando un programa informático de diseño cartográfico, a partir del mencionado plano se obtuvo un mapa base a escala 1:1 ajustado a las hojas topográficas IGM No 3960-12-4 e IGM Nº 3960-12-3 y 18-1 a escala 1:50.000, de los levantamientos de los años 1964 y 1963, respectivamente. Las fuentes utilizadas consisten en fotografías aéreas correspondientes a los años 1967 ( $E=1: 20.000$, Instituto Nacional de Tecnología Agropecuaria) y 1984 $(E=1: 20.000$, Dirección de Geodesia de la 
Provincia de Buenos Aires) e imágenes satelitales QuickBird del Google Earth ${ }^{\circledR}$ de marzo y septiembre de 2004 (resolución espacial menor a 1 metro). Las fotografías aéreas y los mapas históricos se digitalizaron mediante un escáner de alta resolución y luego se georreferenciaron a partir de un mínimo de 15 puntos de control en el sistema de coordenadas planas Gauss Krügger, chequeando además los puntos de control entre las diversas fuentes empleadas. El mismo procedimiento se practicó con las imágenes satelitales.

El área de estudio está constituida por dos áreas menores de acuerdo con la zonificación vigente en la Ordenanza 2005/81 del Partido de Necochea (Figura $N^{0} 1$ ). El área urbana es considerada como la zona destinada a asentamientos humanos intensivos con una densidad de población promedio de 150 habitantes por hectárea, donde se desarrollan usos residenciales, actividades terciarias y producción. El área complementaria es definida como el sector circundante o adyacente al área urbana, en la cual se delimitaron zonas destinadas a reserva para ensanche de la ciudad y a otros usos específicos como agro- pecuario intensivo y clubes de campo, entre otros. Dicha área está destinada a población semiagrupada con una densidad promedio de 30 habitantes por hectárea.

La unidad de análisis fue delimitada en una manzana, la cual ocupa generalmente una superficie de una hectárea. Para evaluar la evolución de la expansión urbana y de los cambios de los usos/cobertura del suelo se construyeron las siguientes categorías:

- Uso urbano: esta categoría está constituida por superficies construidas y sus terrenos asociados, destinados a actividades residenciales, de servicios, comerciales o industriales dentro del continuo urbano residencial. Fue dividida en tres clases de acuerdo con el nivel de ocupación edilicia de cada manzana:

Uso urbano de ocupación baja: 0 a 15\% de ocupación.

Uso urbano de ocupación media: 15,1 a $60 \%$ de ocupación.

Uso urbano de ocupación alta: más de $60 \%$ de ocupación.

Figura $\mathrm{N}^{\circ} 1$

Localización de Necochea y Quequén

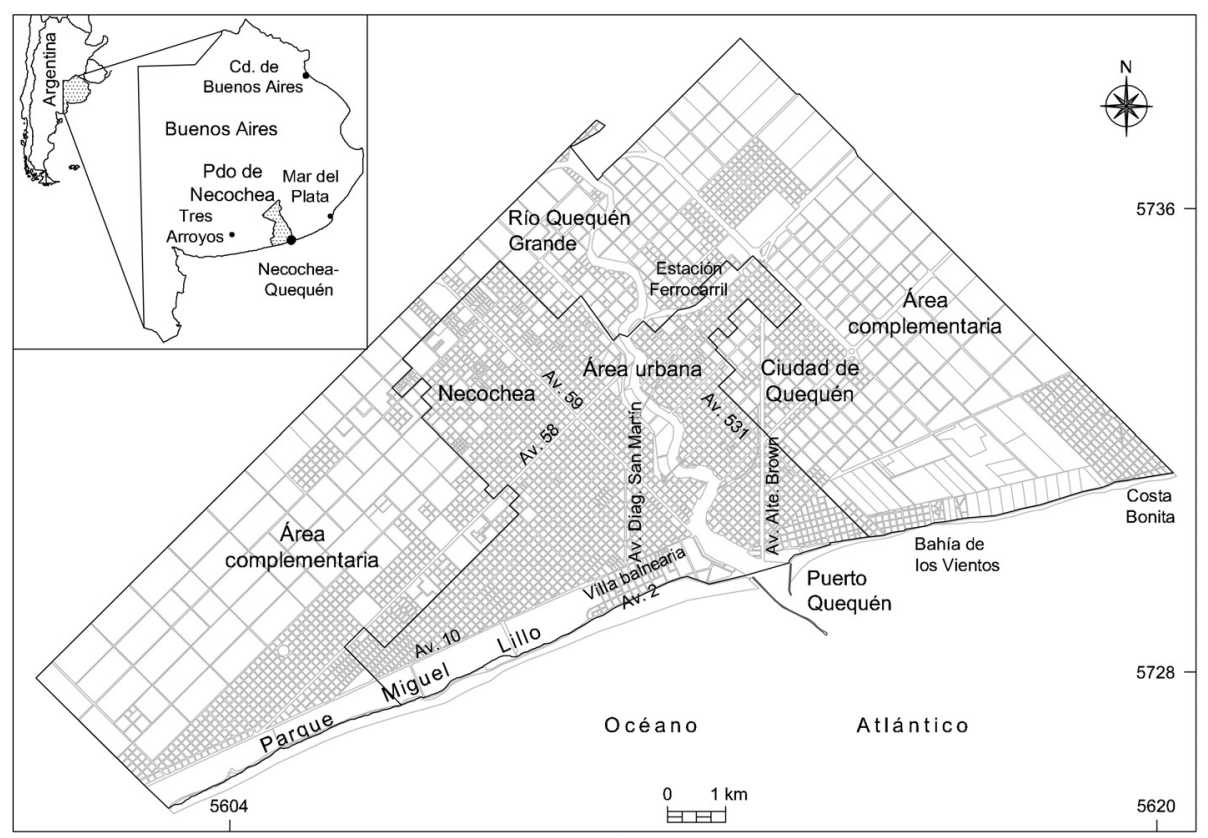

Fuente: Elaboración propia en base al Plano Catastral de la Municipalidad del Partido de Necochea. 
- Uso no urbano: esta categoría abarca tierras sin urbanizar destinadas a usos agroganadero, minero e industrial y a campos de médanos.

- Espacios verdes: esta categoría comprende tierras destinadas a parques y actividades recreativas.

- Cuerpos de agua: esta categoría incluye al río Quequén Grande.

Se realizó la interpretación visual de las fotografías aéreas e imágenes satelitales (Hathout, 2002; Herold et al., 2003) en pantalla sobre el mapa base, de la cual surgió un mapa del uso/cobertura del suelo en los años 1967, 1984 y 2004. En cada uno de ellos se construyeron los polígonos correspondientes para cada capa de información constituida por una categoría. Posteriormente se realizó el análisis comparativo de los cambios, basado en las variaciones de área identificadas. Asimismo, se efectuó un mapa de evolución del uso urbano del cual se obtuvo la expansión urbana desde 1967 a 2004. Finalmente, el análisis efectuado fue integrado con el crecimiento de la población, obtenido a partir de datos de los Censos Nacionales de Población de los años 1960, 1970, 1980, 1991 y 2001, el cual fue complementado con el desarrollo de las principales actividades económicas del área de estudio.

\section{Contexto socioeconómico nacional y regional}

A partir del siglo XVIII comenzó el proceso de poblamiento pampeano especialmente a partir de la superación de los límites de la campaña de Buenos Aires, el río Salado, entre 1740 y 1753 . En este período se instalaron numerosas reducciones jesuíticas hacia el sur de la provincia que luego fueron abandonadas, ocasionando un retroceso del límite a la situación previa (Merlotto y Bértola, 2008).

Durante la década de 1810, los sucesos revolucionarios impidieron la conquista de tierras hacia el sur del río Salado, y luego, a partir de los numerosos problemas económicos, surgió la necesidad de incorporar nuevas tierras para el desarrollo ganadero. Comenzaron los pactos con los pueblos originarios y las peticiones de tierra por los militares y la aristocracia para poder establecerse en ellas. En la década siguiente se produjo la expansión de la frontera ganadera bonaerense y se otorgaron tierras públicas a estancieros a través de la venta o donación en calidad de recompensa o pensiones. Alrededor de 1825, se creó el Partido de Monsalvo desde el Rincón de Ajó hasta el río Quequén Grande y 40 leguas hacia el interior. En el año 1839 se subdividió el mencionado partido, creando cuatro partidos costeros: Ajó, Monsalvo, Mar Chiquita y Lobería (Juárez e Isla, 1999). Posteriormente, en 1865, la Ley 441 dividió la campaña bonaerense al sur del río Salado en 27 partidos y fijó los límites físicos y administrativos de cada uno de ellos, entre ellos el Partido de Necochea (aunque posteriormente fue subdividido y sus límites fueron modificados).

La racionalidad económica-política basada en la expansión de la producción ganadera y en el fortalecimiento del modelo agroexportador, propició el desarrollo de una determinada infraestructura y organización territorial para lograr su consolidación. Se demandaron ferrocarriles y puertos para el traslado de la producción y centros urbanos para proveer servicios a la economía agroganadera. En el año 1865 comenzó la construcción del Ferrocarril Sud con la finalidad de unir la ciudad de Buenos Aires con Chascomús. En los años siguientes, el mismo se fue extendiendo por tramos y en 1886 se inauguró el ramal desde Maipú a Mar del Plata. Para finales del siglo XIX se habían creado las ciudades-puerto de Mar del Plata, Necochea y Bahía Blanca sobre el litoral marítimo y habían surgido numerosos poblados en el interior, cercanos a los ejes ferroviarios, como centros de servicios rurales (Villar, 2002).

\section{Evolución histórica y características socio- económicas del área de estudio}

Las tierras en las cuales se fundó la ciudad de Necochea fueron adquiridas en el año 1836 por el estanciero E. Díaz Vélez mediante su compra a quienes las habían adquirido a partir de la repartición de tierras públicas (Ley de Enfiteusis) pocos años antes. Los asentamientos en el área a mediados del siglo XIX estaban constituidos por los parajes Médano Blanco y La Media Luna y por precarias instalaciones ganaderas (FAUD/UNMDP, 
1997). Tras ser afectados en los años 1872 y 1876 por ataques de grupos de los pueblos originarios, los terratenientes del área elevaron al gobierno provincial un petitorio para la fundación de un pueblo, el cual sería cabecera del partido. En 1877 se sancionó la Ley 1131 mediante la cual se expropiarían tierras en la margen derecha del río Quequén Grande sobre su desembocadura, con destino a la formación del pueblo de Necochea. Un año después, la Ley 1213 autorizó al gobierno a ejecutar la traza del pueblo del modo que halle más conveniente, expropiando una legua (aproximadamente $5.196 \mathrm{~m}$ ) de frente sobre el río desde donde termina el médano existente sobre la costa del mar (debido a los inconvenientes generados por su movilidad), por dos de fondo sobre dicha costa. No obstante, fue recién el 12 de octubre de 1881 cuando Necochea se fundó oficialmente y el 26 de julio de 1911 fue declarada ciudad mediante la Ley $N^{\circ}$ 3352. El plano original de Necochea se conformó por un cuadro de 16 x 16 manzanas con orientación NW-SE y con una plaza central de cuatro manzanas, frente a la cual se erigieron los principales edificios públicos, finalizados hacia 1883 . Un censo realizado pocos días antes de la fundación arrojó una población de 139 personas (Ecos Diarios, 2001).

La fundación de Quequén, la cual perteneció al Partido de Lobería hasta el año 1979 cuando fue traspasada al Partido de Necochea mediante el Decreto-Ley № 9327, estuvo vinculada con la necesidad de sacar la producción ganadera del área a través de un puerto. Desde 1854 se llevaron a cabo sucesivas gestiones para crear un pueblo con puerto sobre la margen izquierda del río Quequén Grande, aunque las iniciativas no prosperaron (Ecos Diarios, 2001). A partir de 1880 los acontecimientos internacionales ocasionaron un freno en la demanda de productos ganaderos propiciando el desarrollo agrícola, por lo cual se reforzó la necesidad anterior de fundar pueblos y ciudades-puertos y extender los ferrocarriles. Entre 1886 y 1911, año en que se inició la obra del puerto Quequén, se sucedieron numerosas concesiones y proyectos para la construcción del puerto y la fundación de su pueblo (aunque ya se emplazaban galpones, depósitos y pequeñas industrias y se habían realizado diversos loteos). Recién en el año 1995, la
Ley 11651 declaró el día 3 de agosto de 1854 como el de fundación de Quequén.

La llegada en el año 1892 del ferrocarril a Quequén y la expansión de la actividad agrícola con sus consiguientes movimientos de población, favorecieron que Necochea se desarrolle relativamente rápido, contando en 1895 con 3.000 habitantes y con 8.500 en 1914 (FAUD/UNMDP, 1997). En la década de 1890, la familia Díaz Vélez comenzó la venta de lotes en un cuadro de $4 \times 4$ manzanas, paralelo a la costa, conformando la villa balnearia Díaz Vélez (FAUD/UNMDP, 1997) (Figura $N^{\circ} 1$ ). En dicha área se había construido en 1885 el primer hotel, surgiendo nuevos a partir del mencionado loteo. Posteriormente, se trazó la Av. Diagonal San Martín para unir el casco fundacional de Necochea con la villa, la cual distaba $1.700 \mathrm{~m}$ del borde sudoeste del casco urbano. En 1914 se inauguró el tranvía que comunicó la ciudad con el balneario, favoreciendo la venta de lotes frente a su recorrido sobre la Av. Diagonal San Martín (Ecos Diarios, 2001). Alrededor del año 1922 se concluyeron todos los ramales ferroviarios que vinculan puerto Quequén con el interior de la provincia y en 1924 se inauguró el primer puente entre ambas ciudades. El mismo reemplazó al servicio de balsas. El advenimiento del automóvil a partir de la década de 1930 y la llegada del ómnibus en 1936, que reemplazó al tranvía, trajeron consigo la pavimentación de las calles principales y el desarrollo de la red de rutas, uniéndose el aglomerado en el año 1945 con la ciudad de Mar del Plata.

Con respecto a la evolución de la trama urbana durante la primera mitad del siglo $X X$, la franja costera de Necochea (hasta la Avenida 10, Figura $N^{\circ} 1$ ) en el año 1949 estaba conformada desde el oeste del río Quequén Grande por una gran zona baldía, por la zona balnearia de aproximadamente $500 \mathrm{~m}$ de frente (seis manzanas por cuatro de fondo) y hacia el sudoeste hasta punta Negra, se emplazaba un campo ininterrumpido de médanos que en su mayor parte ya estaba fijado (Bruno, 2006). La edificación sobre la Av. Diagonal San Martín empezaba a intensificarse. En cambio en Quequén, los sucesivos y problemáticos loteos ocasionaron que el pueblo no presente la estructura urbana típica de las ciudades pampeanas con plaza central, 
edificios públicos y damero, conformándose por fragmentos urbanos relativamente aislados (FAUD/UNMDP, 1997).

Las tierras que actualmente ocupa el parque Miguel Lillo (Figura $\mathrm{N}^{\circ} 1$ ) fueron expropiadas en diferentes años a diversos propietarios y actualmente constituye un bosque urbano de uso público y semipúblico. Fue creado en el año 1948 con el fin de fijar los médanos para posibilitar la expansión urbana, la cual estaba detenida en los primeros años por la existencia de médanos vivos. En el año 1979 fue transferido a la Municipalidad del Partido de Necochea mediante el Decreto 1173. En el parque se localizan campings, circuitos de entrenamiento y áreas de canchas de diversos deportes, clubes, vivero, entre otros.

En cuanto al desarrollo económico, a pesar que en la década de 1880 el Partido de Necochea no poseía producción agrícola, en 1910 ocupó el segundo lugar en volumen de producción luego de Tres Arroyos y con una superficie productiva mayor que otros partidos tradicionalmente agrícolas (FAUD/ UNMDP, 1997). Los cultivos principales eran trigo, avena, lino y maíz, y aunque la ganadería fue desplazada, también era significativa. Desde la fundación de Necochea, surgieron a ambos lados del curso fluvial industrias proveedoras de la población creciente y otras vinculadas con las actividades agroganaderas, entre ellas talleres y metalúrgicas, fábricas de implementos agrícolas, tambos, industrias alimenticias y de bebidas y servicios comerciales y financieros para la exportación. En la actualidad, las actividades administrativas, culturales, comerciales y de servicios en general predominan en Necochea y las industriales en Quequén.

Puerto Quequén comenzó a operar en el año 1922 y su actividad fue afectada por la alternancia de períodos de inacción y períodos de inversión y construcción de infraestructura tendiente a ampliar su capacidad de almacenamiento. Estos períodos se reflejaron en la evolución de las exportaciones (Figura $N^{\circ}$ 2). Entre los años 1962 y 1983 el volumen exportado se mantuvo estable e incluso descendió levemente producto de la falta de renovación de la infraestructura portuaria. En el año 1992 el puerto fue concesionado por
30 años y se efectuaron obras que incrementaron notablemente los volúmenes de exportación (Figura $\mathrm{N}^{\circ} 2$ 2). Las escolleras de abrigo del puerto sufrieron remodelaciones y debieron realizarse diversos dragados en la entrada al mismo, debido a que la acumulación de arena producida por las mismas disminuía su calado. En cuanto a la actividad pesquera, la misma comenzó a realizarse en forma artesanal, y luego de un breve período de apogeo en las décadas de 1960 y 1970, entró en una fase de estancamiento que perdura hasta la actualidad (Ecos Diarios, 2001).

Con respecto a la actividad turística, desde principios del siglo XX las familias aristocráticas de la ciudad de Buenos Aires, así como veraneaban en Mar del Plata, comenzaron también a concurrir a Necochea. Asimismo, la Primera Guerra Mundial dificultó los viajes a Europa y propició el turismo hacia los balnearios bonaerenses. La inauguración del tranvía como medio de comunicación y nexo entre los hoteles del centro y la villa balnearia, actuó atrayendo mayor número de turistas, favoreciéndose la construcción de hoteles y el desarrollo de actividades de ocio como paseos y espectáculos. A finales de la década de 1930 comenzaron a arribar turistas provenientes de la zona agrícola aledaña, quienes estimularon el uso de casa de particulares o de pensión como alojamiento (Ecos Diarios, 2001). La promoción del turismo social con la consiguiente creación de hoteles gremiales y la llegada de los sectores obreros al balneario caracterizó al turismo de sol y playas de finales de los años 1940. Las décadas de 1960 y 1970 fueron las que mayor número de turistas recibieron (Molina Favero, 2004), incrementándose la oferta de servicios y atractivos turísticos. Dicho auge se enmarca en el desarrollo del turismo interno y en particular del turismo de sol y playas que, si bien se manifestó desde períodos anteriores, tuvo su esplendor durante el decenio de 1970 (Merlotto y Bértola, 2008), aunque fue seguido de un estancamiento vinculado con los acontecimientos políticos nacionales hacia finales del mismo. Desde la vuelta a la democracia el municipio propició el desarrollo de la actividad, aunque en la década de 1990 se produjo una nueva caída ya que la paridad cambiaria favoreció el turismo hacia el exterior del país. Asimismo, el crecimiento de los balnearios del este bonaerense y 
su proximidad a la ciudad de Buenos Aires contribuyeron a que Necochea haya visto reducida su capacidad de atracción turística (Molina Favero, 2004).

La política económica del decenio de 1990 produjo un estancamiento general de las actividades económicas generando un importante aumento de la desocupación en gran parte del país. Especialmente, se perjudicaron los pequeños y medianos productores pampeanos con el consiguiente empobrecimiento de la población y el deterioro de su calidad de vida, ocasionando que muchos de ellos dejen el campo y migren hacia los centros urbanos en búsqueda de mejores oportunidades laborales. Entre los años 1988 y 2002, en concordancia con lo sucedido en la región pampeana, las explotaciones agropecuarias en el Partido de Necochea se redujeron un $19 \%$ y aumentó el tamaño medio de las mismas de 554 a 723 ha. A pesar de ello, se ha considerado que el crecimiento económico se halla fuertemente vinculado con la cadena agroexportadora ya que para el año 2004, de los ocho sectores económicos más importantes, seis pertenecían a la cadena agroexportadora, seguidos de la construcción y el comercio (Lucero et al., 2007). Sin embargo, el sector terciario constituye el principal generador de empleo y dentro de este el turismo presenta un gran potencial para incrementar su actividad.

\section{Expansión urbana y cambios del uso/cobertura del suelo}

A partir de la interpretación de las fotografías aéreas del año 1967, se advirtió hacia el sudoeste de Necochea frente al parque M. Lillo, la demarcación de calles principales, manzanas y parcelas y su forestación. A pesar de ello se ha considerado como uso no urbano a gran parte del sector ya que la ocupación prosperó escasamente a lo largo del período estudiado y se observaron parcelas dedicadas a actividades agropecuarias (Figura №3). En cambio en Quequén, Bahía de los Vientos presentaba una ocupación urbana más notoria, la cual era superior en Costa Bonita de acuerdo con la cantidad de construcciones observadas (Figura $\mathrm{N}^{\circ} 4$ ). El frente costero de la villa balnearia en 1967 se hallaba construido con balnearios y hacia el oeste del puerto ya se habían forestado los médanos entre la Av. 2 y la playa (Figura $\mathrm{N}^{\circ}$ 1), impidiendo su movilidad.

En el año 1967 un total de 2.372,94 ha se hallaban urbanizadas, correspondientes al $21,91 \%$ de la superficie del área consi-

Figura $\mathrm{N}^{\circ} 2$

Evolución de las exportaciones en el período 1922-2000 (en millones de toneladas)

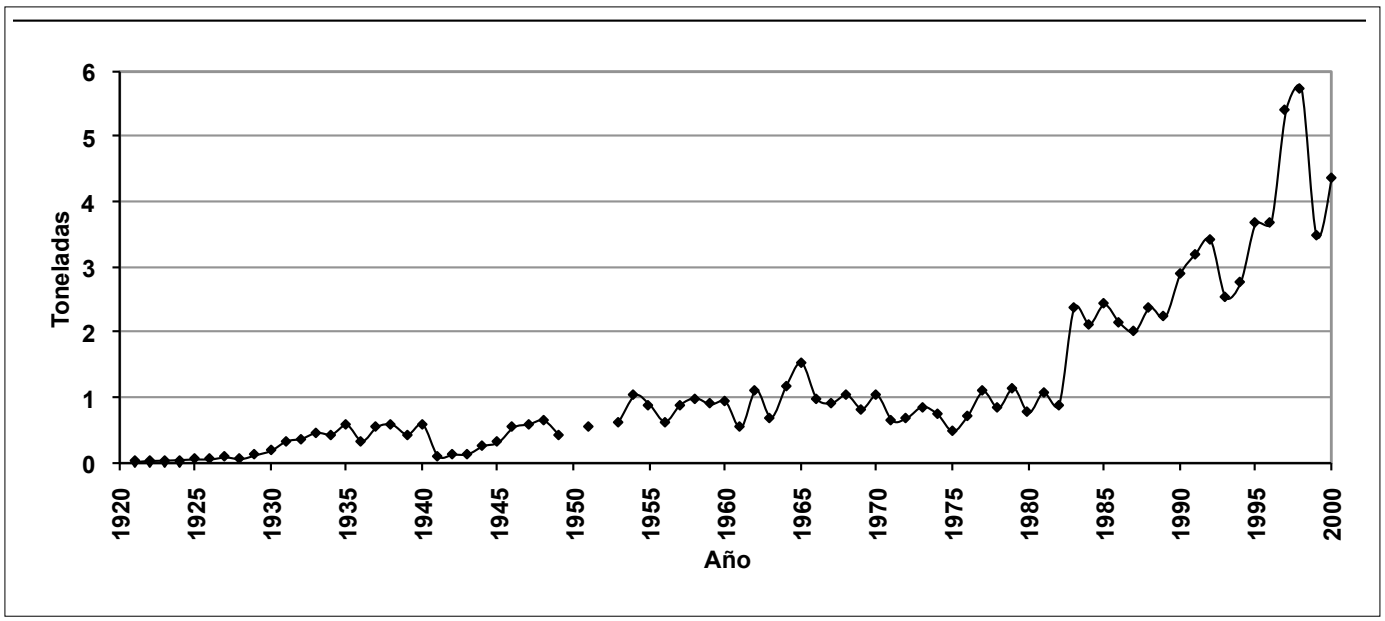

Fuente: Elaboración propia en base a datos de Ecos Diarios (2001). 
derada (Cuadro No 1). Para el año 2004, la ocupación urbana se incrementó a 28,44\% en detrimento del uso no urbano, el cual descendió entre dichos años un 6,49\%. Dicha expansión representa un crecimiento urbano para el período 1967-2004 del 29,62\%, a una tasa media anual de $0,8 \%$. Los límites de la ocupación urbana están comprendidos en general dentro del área urbana considerada por el municipio (Figura $\mathrm{N}^{\circ} 3$ ), excepto en el frente costero. En este, se destacan Bahía de los Vientos y Costa Bonita en Quequén, emplazados en el área complementaria y el sector urbanizado frente al parque M. Lillo en el sudoeste de la aglomeración. En el resto del área de estudio, la mancha urbana se fue extendiendo sobre espacios comprendidos entre la ocupación previa y el límite urbano, y solo en escasos sectores hacia el noroeste la urbanización ocupó tierras del área complementaria.

Los usos agrupados en la categoría no urbana en 1967 abarcaban 7.780,39 ha (71,98\% del área total) (Cuadro $\left.N^{\circ} 1\right)$. Con respecto a la distribución territorial de la ocupación urbana, se observa un eje central y paralelo al río con la mayor densidad de ocupación en cada ciudad, a partir del cual la ocupación decrece hacia ambos lados. La categoría alta densidad comprende el 32,82\% del uso urbano y se extiende en Necochea en casi la totalidad del casco fundacional, a lo largo de las avenidas 59 y diagonal San Martín (Figura $N^{\circ} 1$ ), en la villa balnearia y sobre la ribera del río Quequén Grande, en la zona de su desembocadura (Figura $\mathrm{N}^{\circ} 4$ ). Ciudad de Quequén se caracteriza por presentar una mayor dispersión de las categorías de usos urbanos. La mayor densidad se localiza principalmente hacia el oeste de la av. 531 entre la av. Almirante Brown y el curso fluvial, donde se localiza la infraestructura portuaria, y hacia el noreste, hacia el barrio Estación Quequén, en el cual se emplaza la estación ferroviaria (Figura $N^{0} 4$ ). La categoría más desarrollada es la de baja densidad, la cual ocupa un $41,63 \%$ del uso urbano. Se extiende a lo largo del frente costero del área: en Costa Bonita, en la zona central del núcleo urbano Necochea-Quequén sobre ambas riberas del río Quequén Grande y en los alrededores de las ciudades. Se destaca el sector noroeste por la ausencia de dicha categoría ya que los usos no urbanos se presentan a continuación de la densidad media o alta. Las hectáreas con ocupación media abarcan el 25,56\% del uso urbano (Cuadro $\mathrm{N}^{\circ} 2$ ) y se disponen entre las categorías alta y baja (Figura $N^{\circ} 4$ ).

En el período 1967-1984 un total de 481,14 ha fueron incorporadas al uso urbano a una tasa media de 28,3 ha/año, totalizando $2.853,91$ ha urbanizadas (Cuadro $N^{\circ} 1$ ). Para 1984 la expansión urbana se manifestó principalmente en el noroeste de Necochea y en menor medida en Quequén, donde se ocuparon espacios entre el límite del área urbana y la ocupación del año 1967. Se destaca la incorporación de manzanas en Bahía de los Vientos y Costa Bonita (Figura No5). Asimismo, se manifestó un intenso proceso de den-

Cuadro $\mathrm{N}^{\circ} 1$

Usos del suelo en los años 1967, 1984 y 2004

\begin{tabular}{|l|r|r|r|r|r|r|}
\hline \multirow{2}{*}{$\begin{array}{l}\text { Uso/cobertura del } \\
\text { suelo }\end{array}$} & \multicolumn{2}{|c|}{1967} & \multicolumn{2}{c|}{1984} & \multicolumn{2}{c|}{2004} \\
\cline { 2 - 7 } & Hectáreas & Porcentaje & \multicolumn{1}{c|}{ Hectáreas } & Porcentaje & Hectáreas & Porcentaje \\
\hline Uso urbano & $2.372,77$ & 21,95 & $2.853,91$ & 26,40 & $3.075,58$ & 28,44 \\
\hline Uso no urbano & $7.780,39$ & 71,98 & $7.299,24$ & 67,53 & $7.083,08$ & 65,50 \\
\hline Espacios verdes & 466,62 & 4,32 & 466,62 & 4,32 & 465,21 & 4,30 \\
\hline Cuerpos de agua & 189,88 & 1,76 & 189,88 & 1,76 & 189,88 & 1,76 \\
\hline Área total & $10.809,66$ & 100,00 & $10.809,66$ & 100,00 & $10.813,74$ & 100,00 \\
\hline
\end{tabular}

Fuente: Elaboración propia. 
Cuadro $\mathrm{N}^{\circ} 2$

Ocupación urbana en los años 1967, 1984 y 2004

\begin{tabular}{|l|r|r|r|r|r|r|}
\hline \multirow{2}{*}{$\begin{array}{l}\text { Ocupación del uso } \\
\text { urbano }\end{array}$} & \multicolumn{2}{|c|}{1967} & \multicolumn{2}{c|}{1984} & \multicolumn{2}{c|}{2004} \\
\cline { 2 - 7 } & hectáreas & Porcentaje & Hectáreas & Porcentaje & Hectáreas & Porcentaje \\
\hline Ocupación baja & 987,68 & 41,63 & 828,77 & 29,04 & 652,79 & 21,23 \\
\hline Ocupación media & 606,41 & 25,56 & 667,68 & 23,40 & 586,06 & 19,06 \\
\hline Ocupación alta & 778,68 & 32,82 & $1.357,47$ & 47,57 & $1.836,72$ & 59,72 \\
\hline
\end{tabular}

Fuente: Elaboración propia.

Figura $\mathrm{N}^{\circ} 3$

Expansión urbana entre los años 1967 y 2004

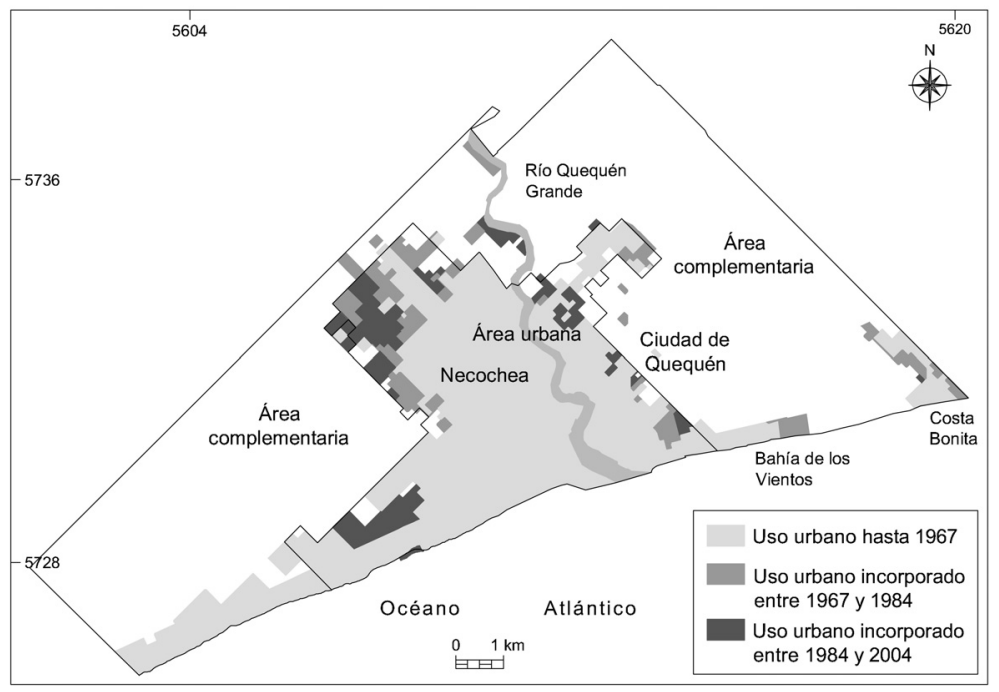

Fuente: Elaboración propia.

sificación urbana. La categoría baja densidad disminuyó a 29,04\% y la alta densidad se incrementó a 47,57\%, pasando esta de 778,68 ha en el año 1967 a $1.357,47$ ha en 1984 (Cuadro $N^{\circ} 2$ ). La ocupación de densidad media descendió levemente (2\%). Con respecto a la distribución de la ocupación urbana, la densidad alta se extendió sobre la media y la baja del corte anterior, generándose en Necochea un continuo urbano consolidado entre el casco fundacional y la villa balnearia que desciende en densidad hacia el oeste y a lo largo del parque M. Lillo. Hacia el noroeste el gradiente es más abrupto (Figura $N^{\circ} 5$ ). La expansión de la ocupación en Quequén fue reducida, no obstante se densificó notablemente. La clase ocupación baja está mayormente representada en Bahía de los Vientos y Costa Bonita (Figura No 5 ).

La ocupación urbana en el año 2004 abarcaba 3.075,58 ha, correspondientes al $28,44 \%$ del área estudiada (Cuadro No 1). Se incorporaron a la urbanización 221,66 ha a una tasa media de 11,08 ha/año, valor significativamente menor al del período anterior. La expansión urbana mantuvo en Necochea la tendencia del período anterior al incorporar un sector importante frente al parque $M$. Lillo. Se observó además un nuevo asenta- 
Figura $\mathrm{N}^{\circ} 4$

Uso/cobertura del suelo en el año 1967

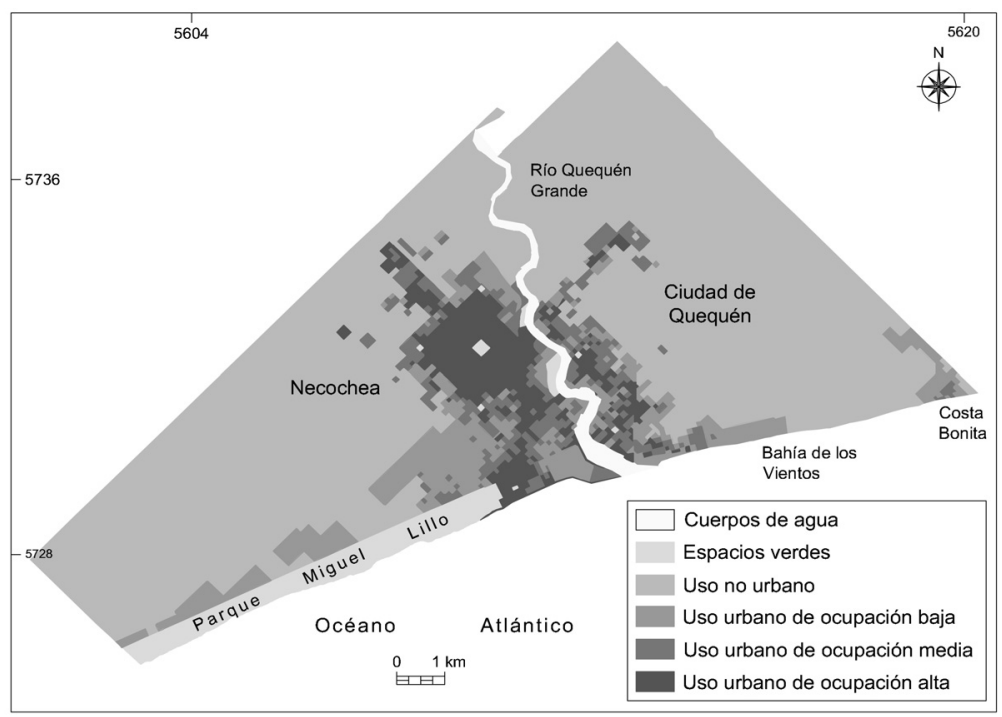

Fuente: Elaboración propia.

miento en el noreste sobre el río Quequén Grande, mientras que Quequén adicionó algunas hectáreas hacia el este (Figura $\mathrm{N}^{\circ} 3$ ). La densificación urbana fue notoria en toda el área estudiada (Figura $N^{\circ}$ 6). La categoría ocupación alta alcanzó el 59,72\% del uso urbano, mientras que el resto de las categorías disminuyeron. La baja densidad descendió a $21,23 \%$ y la media a $19,06 \%$ (Cuadro $N^{\circ} 2$ ). La ocupación baja continúa predominando frente al Parque M. Lillo y en Costa Bonita y se encuentra dispersa en puntos alrededor de la aglomeración, así como también sobre las riberas del curso fluvial. Se destaca un área de 5,5 ha entre la línea de costa y el parque M. Lillo con ocupación de alta densidad. La misma constituye el Barrio Cerrado Médanos, el cual fue loteado a mediados de la década del 90 produciendo un leve descenso de la superficie del parque (Figura $\mathrm{N}^{\circ} 6$ ).

En cuanto al desarrollo de la vegetación sobre el frente costero y sobre los médanos, en el año 1967 el área boscosa del parque M. Lillo no alcanzaba a cubrir el área urbana de Necochea. Hacia el oeste predominaban los médanos vivos sobre el sector costero conformando una estrecha franja. Entre ella y la av. 10 (Figura № 1), los médanos se haIlaban cubiertos por vegetación herbácea y arbustiva. Durante el período 1967-1984 el área boscosa se extendió aproximadamente
$2.500 \mathrm{~m}$ hacia el sudoeste y se expandió la vegetación herbácea y arbustiva. Para el año 2004, la superficie forestada no se incrementó. En Quequén, entre Bahía de los Vientos y Costa Bonita se advirtió en las fotografías aéreas de 1967 que parte del sector había sido forestado. Sin embargo, la vegetación creció escasamente hasta 1984. Desde entonces, la cubierta vegetal manifestó un importante crecimiento y expansión ya que para el año 2004 se observó una amplia franja de médanos costeros cubiertos por vegetación arbórea, arbustiva y herbácea. La cubierta vegetal disminuye hacia el continente, encontrándose médanos parcialmente fijados y luego la misma vuelve a aumentar. Solo en un pequeño sector al oeste de Costa Bonita se emplazan médanos vivos con escasa vegetación.

Con respecto al crecimiento poblacional, las ciudades de Necochea y Quequén constituyen un aglomerado urbano de tamaño intermedio desde la década de 1980 cuando su población superó los 50.000 habitantes. El crecimiento poblacional fue muy alto en ambas localidades hasta el año 1980 ya que para los períodos 1960-1970 y 1970-1980 superó el $30 \%$ en Necochea y fue de alrededor del 25\% en Quequén (Cuadro № 3). Estos valores son significativamente superiores a los del crecimiento de la población total del país $(17 \%)$. Por consiguiente, entre 1960 y 1980 
Figura $\mathrm{N}^{\circ} 5$

Uso/cobertura del suelo en el año 1984

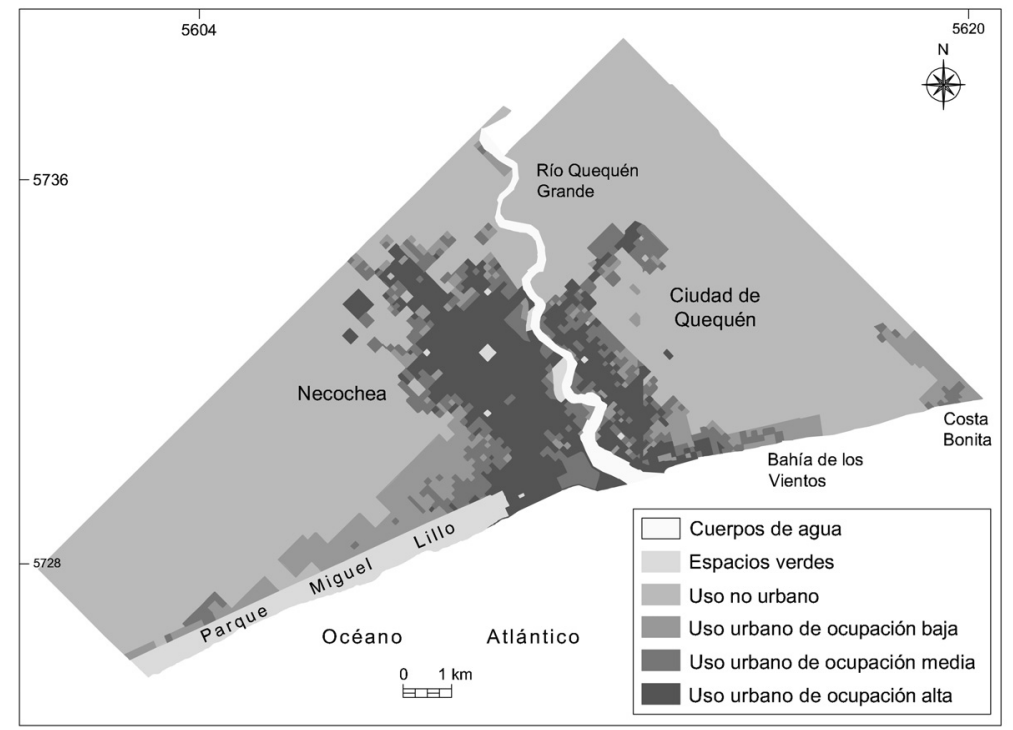

Fuente: Elaboración propia.

Figura $\mathrm{N}^{\circ} 6$

Uso/cobertura del suelo en el año 2004

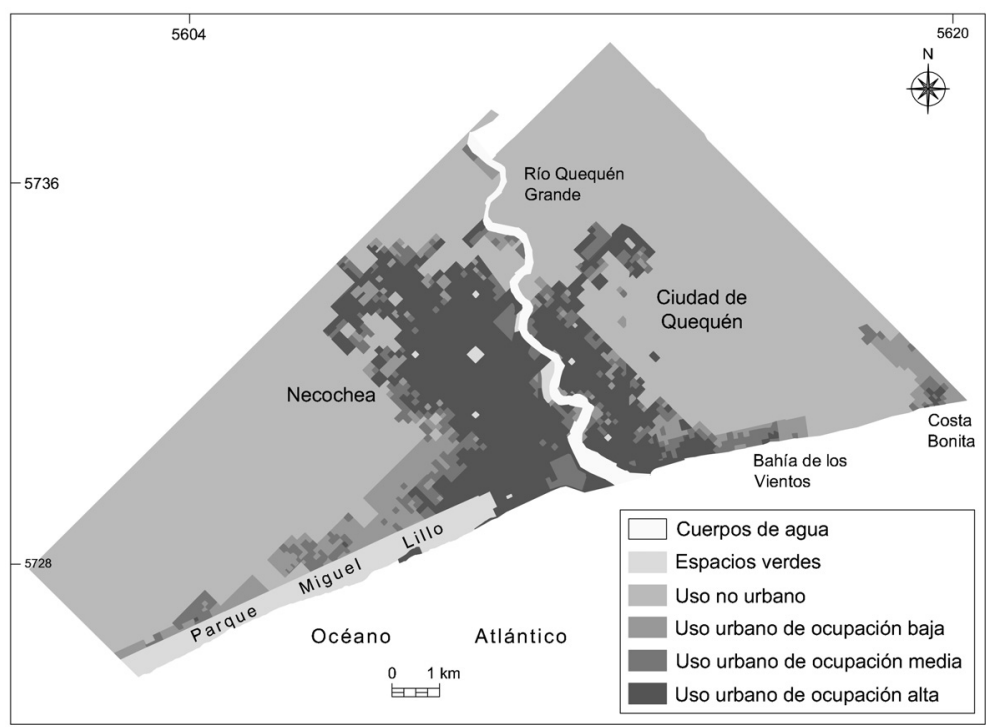

Fuente: Elaboración propia.

el núcleo urbano registró un incremento de 25.768 habitantes, Necochea de 21.620 y Quequén de 4.148, el cual se reflejó en la expansión y densificación del área de estudio.

A partir del año 1980 el crecimiento poblacional del área fue menor, siendo de
$17,35 \%$ y $19,78 \%$ para el año 1991 para $\mathrm{Ne}$ cochea y Quequén, respectivamente, superior al de Argentina (13,9\%) (INDEC, 2005). Entre 1991 y 2001 el crecimiento fue de $9,7 \%$ y $8,34 \%$ para ambas ciudades (Cuadro № 3 ), similar al de la población del país $(9,1 \%)$. 
Desde 1980 al año 2001 la población del conjunto urbano se incrementó en 18.169 habitantes (INDEC, 2005). Si bien el crecimiento es significativo, es menor que el de los períodos anteriores, en concordancia con el descenso del ritmo de expansión y densificación urbana.

En suma, entre los años 1960 y 2001, la población del aglomerado Necochea-Quequén creció un $119,04 \%$ a una tasa media anual de 2,9\%. Por su parte, la ocupación del suelo por el uso urbano creció a una tasa media anual de 0,8\% durante el período 1967-2004. Estos resultados evidencian que en el área de estudio, el proceso de densificación de la ocupación urbana es notablemente superior al de la expansión de la mancha urbana. Estos resultados son diferentes a los hallados en grandes área metropolitanas de Europa. Catalán et al. (2008) estimaron en la región metropolitana de Barcelona (España), que el crecimiento de la ocupación urbana entre los años 1993 y 2000 fue seis veces mayor que el crecimiento de la población. Este fenómeno fue precedido por un intenso proceso de densificación urbana en décadas previas y es atribuido al paso de las anteriormente segundas residencias a primeras residencias, favorecido por la mejora de las infraestructuras de comunicación y de las nuevas tecnologías (Badia et al., 2010).

Puede estimarse que el crecimiento poblacional observado está vinculado en gran medida con las migraciones desde el ámbito rural del Partido de Necochea hacia el aglomerado Necochea-Quequén. La población del Partido de Necochea sin tener en cuenta ambos centros urbanos, ha presentado un crecimiento negativo (Cuadro $N^{\circ} 3$ ), a excepción del período 1980-1991. En el último período intercensal alcanzó el máximo valor $(-27,21 \%)$, el cual refleja la crisis del sector agropecuario de la década de los años 90. Asimismo, se estima que el aglomerado urbano actúa atrayendo población desde otros partidos ya que como ciudad intermedia posee todos los servicios y equipamientos de ciudades de mayor tamaño y mejores oportunidades laborales que poblados menores. Lucero et al. (2007) consideran que habitantes de ciudades de mayor tamaño que cambian de residencia también estarían arribando a Necochea y Quequén para asentarse en ellas de forma permanente.

A pesar de las sucesivas crisis económicas que afectaron durante el siglo XX al país, el sector terciario o de servicios y sobre todo el turismo de sol y playas siempre ha representado, en mayor o menor medida, una fuente de empleo demandante de mano de obra estacional, la cual muchas veces es satisfecha por población que no retorna a su lugar de origen. Del mismo modo, las actividades primarias vinculadas con la exportación, aunque esta ha presentado épocas de estancamiento o incluso retroceso, han actuado atrayendo trabajadores en puerto Quequén.

\section{Cuadro $\mathrm{N}^{\circ} 3$}

Población y crecimiento en Necochea, Quequén y en el resto del Partido de Necochea

\begin{tabular}{|l|r|r|r|r|r|r|}
\hline \multirow{2}{*}{ Año } & \multicolumn{2}{|c|}{ Necochea } & \multicolumn{2}{c|}{ Quequén } & \multicolumn{2}{c|}{ Resto del Partido } \\
\cline { 2 - 7 } & Población & Crecimiento (\%) & Población & Crecimiento (\%) & Población & Crecimiento (\%) \\
\hline 1960 & 29.319 & - & 7.589 & - & 14.181 & - \\
\hline 1970 & 38.868 & 32,57 & 9.299 & 22,53 & 11.277 & $-20,48$ \\
\hline 1980 & 50.939 & 31,06 & 11.737 & 26,22 & 10.408 & $-7,71$ \\
\hline 1991 & 59.775 & 17,35 & 14.058 & 19,78 & 11.305 & 8,62 \\
\hline 2001 & 65.615 & 9,77 & 15.230 & 8,34 & 8.251 & $-27,01$ \\
\hline
\end{tabular}

Fuente: Elaboración propia en base a datos del INDEC (2005). 
La evolución de los metros cuadrados construidos permite apreciar el paralelismo con los resultados del crecimiento urbano hallados (Figura $N^{\circ} 7$ ). Hasta el año 1984 se efectuaron importantes edificios en propiedad horizontal y barrios de viviendas, con un auge de la construcción de viviendas individuales debido a facilidades crediticias (Ecos Diarios, 2001). A partir de mediados de la década de 1980 la construcción comenzó a decaer, en coincidencia con el comportamiento del crecimiento urbano. Asimismo, la industria de la construcción constituye otra fuente de mano de obra sustancial. Dicha actividad ha sido considerada como un importante dinamizador de la economía local entre los años 1974 y 1984 (Ecos Diarios, 2001). El fuerte crecimiento en la ocupación del espacio en el área de estudio registrado hasta el año 1984 se enmarca, además, en el desarrollo del turismo interno y en particular del turismo de sol y playas que, si bien se manifestó desde décadas anteriores, tuvo su auge durante la década de 1970. Este proceso fue acompañado por una intensa expansión urbana en la costa atlántica bonaerense (Merlotto y Bértola, 2008).

En cambio, durante la década de 1990 se observó la alternancia de años de fuerte incremento de la construcción, comparables a los de los años 70 y otros con notables descensos y actividad muy escasa (Figura $N^{\circ} 7$ ). Asimismo, la desaceleración del crecimiento urbano puede vincularse con el empobrecimiento general de la población debido al estancamiento de la economía del país y de la actividad turística que afectó a la costa atlántica bonaerense (Verón y Merlotto, 2009).

En resumen, se considera que la distribución de los usos del suelo urbanos observados en el año 1967 aún reflejaban una ocupación ligada a las actividades agropecuaria y balnearia (casco, villa, puerto) y al desarrollo de las vías de comunicación y medios de transporte (estación de tren, av. Diagonal San Martín) (Figura No 1). Esta "dicotomía" fue observada en los años 50 por Ecos Diarios (2001) en referencia a que la ciudad miraba más al campo que al mar. Esta visión perdura hasta el presente. Sin embargo, se estima que dicha dicotomía representa más bien una dualidad económica que se plasmó en el desarrollo urbano del aglomerado y que posiblemente estaba más marcada en el pasado ya que la promoción en favor del desarrollo del turismo desde la segunda década del siglo $\mathrm{XX}$ y sobre todo en la segunda mitad del mismo, permitió que la ciudad se constituyera en un destacado centro turístico a nivel nacional. Es por ello que la importancia del sector agroexportador no implicó un olvido del sector costero, como sí se verificó en partidos ganaderos del este bonaerense, el cual se tradujo en falta de desarrollo y consecuencias económicas negativas para el ámbito litoral (Villar et al., 1993; Merlotto y Bértola, 2008).

Figura $\mathrm{N}^{\circ} 7$

Evolución de la construcción en el período 1970-2000

(En miles de $\mathrm{m}^{2}$ )

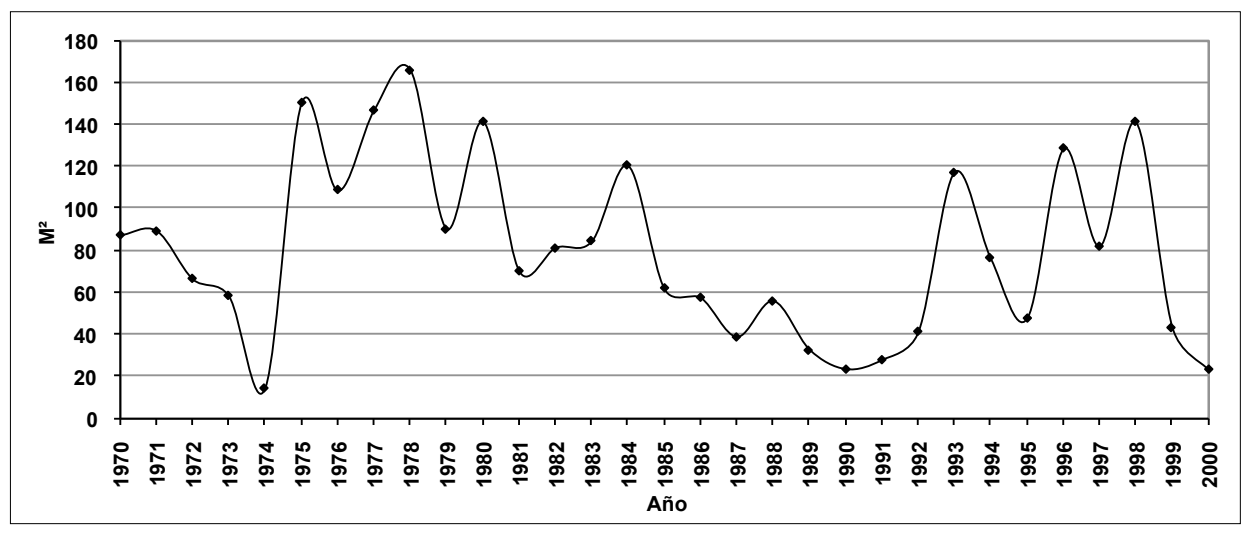

Fuente: Elaboración propia en base a datos de Ecos Diarios (2001). 
No obstante, la contribución de la actividad terciaria al producto bruto geográfico del conjunto del Partido de Necochea es pequeña dada la importancia del sector agropecuario exportador.

La ocupación urbana de Quequén está mayormente vinculada con el puerto y a las actividades industriales derivadas, las cuales también se reflejaron en la expansión y densificación del núcleo urbano. En cuanto a la actividad turística, Costa Bonita surgió como un balneario a mediados del siglo XX y su desarrollo ha permanecido estancado. Actualmente están efectuándose emprendimientos inmobiliarios en Bahía de los Vientos, por consiguiente, el turismo estaría cobrando importancia en Quequén, en la cual podrían manifestarse a corto plazo procesos de expansión y densificación urbanas. La actividad sería una nueva fuente de ingresos y empleo significativa para dicha localidad.

\section{Conclusiones}

En el presente estudio se evaluó la expansión de la mancha urbana del aglomerado Necochea-Quequén así como los cambios en el uso/cobertura del suelo entre los años 1967, 1984 y 2004. Durante los 37 años estudiados, la mancha urbana creció un $29,62 \%$, a una tasa media anual de $0,8 \%$. La tasa media de crecimiento del uso urbano fue de 28,3 ha/año durante el período 19671984. La misma disminuyó notablemente en las dos décadas posteriores, registrándose una tasa de crecimiento urbano de 11,08 ha/ año entre 1984 y 2004. El espacio ocupado por el uso urbano se incrementó de 21,95 a $28,44 \%$ del total del área, en detrimento del uso no urbano, destinado a actividades agroganaderas, mineras e industriales y a campos de médanos. El uso del suelo destinado a espacios verdes descendió levemente debido al desarrollo de un emprendimiento inmobiliario en la década de 1990 sobre los médanos frontales, entre la línea de costa y el parque M. Lillo.

El uso urbano de ocupación alta conforma un continuo urbano sobre las zonas centrales de ambas ciudades con un eje hacia el noreste y otro hacia el noroeste en Quequén y Necochea, respectivamente. Las zonas de uso urbano con menor ocupación constituyen pequeños sectores de no más de tres hectáreas que rodean el aglomerado NecocheaQuequén. Ambas riberas del río Quequén Grande hacia el noroeste y el frente costero, sobre el parque M. Lillo y desde Bahía de los Vientos hacia el este, constituyen ejes de crecimiento en los cuales el uso urbano de ocupación baja se incrementa aunque aún son escasas las hectáreas con ocupación alta. El importante crecimiento del área ocupada por la categoría ocupación alta (de 32,82\% al $59,72 \%$ ) y la significativa reducción del área adjudicada a la categoría de ocupación baja (de $41,63 \%$ a $21,23 \%$ ), evidencian el intenso proceso de densificación urbana atravesado por el aglomerado Necochea-Quequén, el cual podría extenderse hacia dichos ejes. Asimismo, la categoría de ocupación media descendió levemente durante el período estudiado.

Con respecto a la ocupación de los médanos frontales por la vegetación, entre Bahía de los Vientos y Costa Bonita se advirtió durante el período estudiado un notable crecimiento y expansión de la forestación hasta 1984. Posteriormente, predominó la densificación por sobre la ampliación del área cubierta por vegetación. La forestación del parque M. Lillo se extendió en superficie hasta el límite del área complementaria a la urbana hasta el año 1984, pero posteriormente predominó la densificación del mismo.

En cuanto a los factores que han impulsado el desarrollo urbano, el fortalecimiento del sector de la construcción, del turismo o del sector exportador en diferentes cortes históricos se han plasmado en la evolución urbana y poblacional del área de estudio. El crecimiento de la población acompañó y superó significativamente el ritmo de crecimiento urbano, evidenciando que el proceso de densificación de la ocupación es notablemente superior al del crecimiento de la mancha urbana. Entre los años 1960 y 2001, la población del aglomerado Necochea-Quequén creció un $119,04 \%$ a una tasa media anual de 2,9\%. Hasta el año 1980 el crecimiento de población fue muy alto con valores de $25 \%$ a $30 \%$, casi duplicando las tasas del total del país. Luego, el crecimiento de la población comenzó a disminuir y entre los años 1991 y 
2001, la población creció alrededor del 9\%, valor similar al de la población del país. La población del resto del partido ha presentado un crecimiento negativo y en el último período intercensal alcanzó el máximo valor, reflejando la crisis del sector agropecuario de la década de los años 90 y favoreciendo las migraciones desde el ámbito rural al urbano.

Se considera que la distribución de los usos del suelo urbano observados en el año 1967 aún reflejaban una ocupación ligada a las actividades agropecuaria y balnearia (casco, villa, puerto) y al desarrollo de las vías de comunicación y medios de transporte (estación de tren, av. Diagonal San Martín), ya que la dualidad económica de la aglomeración Necochea-Quequén se plasmó fuertemente en el desarrollo urbano en el pasado. Sin embargo, la importancia del sector agroexportador no implicó un olvido del sector costero. La promoción en favor del desarrollo del turismo desde la segunda década del siglo XX y sobre todo en la segunda mitad del mismo, permitió que la ciudad se constituyera en un destacado centro turístico a nivel nacional, atenuándose las diferencias urbanas entre el centro y la villa.

La metodología utilizada ha permitido apreciar, mediante el estudio de la expansión urbana y de los cambios en el uso/cobertura del uso, la manifestación en el espacio urbano de las actividades socioeconómicas predominantes a lo largo del tiempo. Conocer la dinámica urbana del área de estudio y los factores que han impulsado su crecimiento, resultan de fundamental importancia en el contexto actual de desarrollar un plan de manejo costero integrado del litoral bonaerense.

\section{Referencias bibliográficas}

AZÓCAR, G.; SANHUEZA, R. y HENRÍQUEZ, C. Cambio en los patrones de crecimiento en una ciudad intermedia: el caso de Chillán en Chile Central. EURE, 2003, Vol. 29, № 87, p. 79-92.

AZÓCAR, G.; SANHUEZA, R. y HENRÍQUEZ, C. Patrones de crecimiento urbano en la Patagonia chilena: el caso de la ciudad de Coyhaique. Revista de Geografía Norte Grande, 2010, No 46, p. 85-104.
BADIA, A.; ESTANY, G.; OTERO, I. Y BOADA, M. Estudio del crecimiento urbano disperso y los cambios en el paisaje en Matadera (Región Metropolitana de Barcelona). Boletín de la Asociación de Geógrafos Españoles, 2010, № 54, p. 301-321.

BATISANI, N. \& YARNAL, B. Urban expansion in Centre County, Pennsylvania: Spatial dynamics and landscape transformations. Applied Geography, 2009, Vol. 29, № 2, p. 235-249.

BHATTA, B.; SARASWATI, S. \& BANDYOPADHYAY, D. Quantifying the degree-of-freedom, degree-of-sprawl, and degree-of-goodness of urban growth from remote sensing data. Applied Geography, 2010, Vol. 30, № 1, p. 96-111.

BLASCHKE, T. Object based image analysis for remote sensing. Journal of Photogrammetry and Remote Sensing, 2010, Vol. 65, No 1, p. 2-16.

BOLAY, J.-C. \& RABINOVICH, A. Intermediate cities in Latin America risk and opportunities of coherent urban development. Cities, 2004, Vol. 21, No 5, p. 407-421.

BRUNO, P. Una tesis de planeamiento de los años 50. Planeamiento y Urbanización de Necochea-Quequén (Argentina). Antonio Bonet y Jorge Ferrari Hardoy arquitectos. Perspectivas Urbanas, 2006, № 7, p. 15-31.

CATALÁN, B.; SAURí, D. \& SERRA, P. Urban sprawl in the Mediterranean? Patterns of growth and change in the Barcelona Metropolitan Region 1993-2000. Landscape and Urban Planning, 2008, Vol. 85, No 3-4, p.174-184.

CRAWFORD, T.W. Where does the coast sprawl the most? Trajectories of residential development and sprawl in coastal North Carolina, 1971-2000. Landscape and Urban Planning, 2007, Vol. 83, No 4, p. 294-307.

DENNISON, W.C. Environmental problem solving in coastal ecosystems: A paradigm shift to sustainability. Estuarine, Coastal and Shelf Science, 2008, Vol. 77, № 2, p. 185-196. 
ECOS DIARIOS. Diario de los 120 años de Necochea. Necochea: Ecos Diarios, 2001.

FAUD/UNMDP. Habitar Necochea-Quequén. Diagnóstico y propuesta para un desarrollo sustentable. Mar del Plata: Facultad de Arquitectura, Urbanismo y Diseño, Universidad Nacional de Mar del Plata, 1997.

FUJIHARA, M.; HARA, K. \& SHORT, K.M. Changes in landscape structure of "yatsu" valleys: a typical Japanese urban fringe landscape. Landscape and Urban Planning, 2005, Vol. 70, No 3-4, p. 261-270.

GILLIES, R.R.; BOX, J.B.; SYMANZIK, J. \& RODEMAKER, E.J. Effects of urbanization on the aquatic fauna of the Line Creek watershed, Atlanta-a satellite perspective. Remote Sensing of Environment, 2003, Vol. 86, № 3, p. 411-422.

HARA, Y.; TAKEUCHI, K. \& OKUBO, S. Urbanization linked with past agricultural landuse patterns in the urban fringe of a deltaic Asian mega-city: a case study in Bangkok. Landscape and Urban Planning, 2005, Vol. $73, N^{\circ} 1$, p. 16-28.

HATHOUT, S. The use of GIS for monitoring and predicting urban growth in East and West St Paul, Winnipeg, Manitoba, Canada. Journal of Environmental Management, 2002, Vol. 66, No 3, p. 229-238.

HEROLD, M.; GOLDSTEIN, N.C. \& CLARKE, K.C. The spatiotemporal form of urban growth: measurement, analysis and modeling. Remote Sensing of Environment, 2003, Vol. 86, No 3, p. 286-302.

HERRERA, V. Estudio del crecimiento urbano de la ciudad de Valdivia (Chile) a través del uso integrado de imágenes de satélite, SIG y equipos de GPS. Revista de Teledetección, 2001, № 15. Disponible en Internet: http://www.aet.org.es/?q=revista15-8

INSTITUTO NACIONAL DE ESTADÍSTICA Y CENSOS (INDEC). Base Usuarios 2001. Base de Datos Censo Nacional de Población, Hogares y Viviendas 2001. Buenos Aires: CDrom, REDATAM+SP, 2005.
JUÁREZ, V. e ISLA, F.I. Evolución histórica del núcleo urbano de Villa Gesell. Revista Geográfica, 1999, № 125, p. 49-60.

JUÁREZ, V.; CORTIZO, L. e ISLA, F.I. Evolución urbana del sector costero sur de General Pueyrredón. Revista Geográfica, 2001, № 129, p.143-156.

LÓPEZ, E.; BOCCO, G.; MENDOZA, M. \& DUHAU, E. Predicting land-cover and land-use change in the urban fringe. A case in Morelia city, Mexico. Landscape and Urban Planning, 2001, Vol. 55, № 4, p. 271-285.

LUCERO, P.; MIKKELSEN, C. Y SABUDA, $F$. Necochea-Quequén en los inicios del siglo XXI. En: CACOPARDO, F. (Editor). Vencer la pobreza. Necochea-Quequén: una propuesta de desarrollo local y promoción humana para ciudades intermedias argentinas. Mar del Plata: Gráfica Altamirano, 2007, p. 29-64.

MARTINUZZI, S.; GOULD, W.A. \& RAMOS GONZÁLEZ, O.M. Land development, land use, and urban sprawl in Puerto Rico integrating remote sensing and population census data. Landscape and Urban Planning, 2007, Vol. 79, No 3-4, p. 288-297.

MERLOTTO, A. y BÉRTOLA, G.R. Consecuencias socio-económicas asociadas a la erosión costera en el balneario Parque Mar Chiquita, Argentina. Investigaciones Geográficas, 2007, No 43, p. 143-160.

MERLOTTO, A. y BÉRTOLA, G.R. Evolución urbana y su influencia en la erosión costera en el balneario Parque Mar Chiquita, Argentina. Papeles de Geografía, 2008, № 47-48, p.143-158.

MERLOTTO, A. \& BÉRTOLA, G.R. Coastline evolution at Balneario Parque Mar Chiquita, Argentina. Ciencias Marinas, 2009, Vol. $35, N^{\circ} 3$, p. 271-286.

MOLINA FAVERO, G. La reestructuración de un espacio: Refuncionalización en la zona del frente marítimo de la ciudad de Necochea. Mar del Plata: Tesis de grado Licenciatura en Geografía, Facultad de Humanidades, Universidad Nacional de Mar del Plata, 2004. 
MORELLO, J.; BUZAI, G.D.; BAXENDALE, C.A.; RODRÍGUEZ, A.F.; MATTEUCCI, S.D.; GODAGNONE, R.E. \& CASAS, R.R. Urbanization and the consumption of fertile land other ecological changes: the case of Buenos Aires. Environment and Urbanization, 2000, Vol. 12, No 2, p. 119-131.

NASARRE VÁZQUEZ, M.E. y BADIA PERPINYA, A. Una aproximación al crecimiento de áreas urbanas a través de fotografía aérea y de Sistemas de Información Geográfica. La ciudad de Tarrassa como caso de estudio. Cuadernos Geográficos, 2006, № 39, p. 185201.

ORTIZ LOZANO, L.; GRANADOS BARBA, A.; SOLÍS WEISS, V. \& GARCÍA SALGADO, M.A. Environmental evaluation and development problems of the Mexican Coastal Zone. Ocean \& Coastal Management, 2005, Vol. 48, № 2, p. 161-176.

PASCUAL AGUILAR, J.A.; AÑÓ, C.; VALERA, A. \& SÁNCHEZ, J. Urban growth dynamics (1956-1998) in mediterranean coastal regions: the case of Alicante, Spain. In: KEPNER, W.G.; RUBIO, J.L.; MOUAT, D.A. \& PEDRAZZINI, F. (Editors). Desertification in the Mediterranean Region: a Security Issue. Dordrecht: Springer, 2006, p. 325-340.

PERILLO, G.M.E.; PÉREZ, D.E.; PICCOLO, M.C.; PALMA, E.D. \& CUADRADO, D.G. Geomorphologic and physical characteristics of a human impacted estuary: Quequén Grande River Estuary, Argentina. Estuarine, Coastal and Shelf Science, 2005, Vol. 62, № 1-2, p. 301-312.

RAYBURN, A.P. \& SCHULTE, L.A. Landscape change in an agricultural watershed in the U.S. Midwest. Landscape and Urban Planning, 2009, Vol. 93, № 2, p. 132-141.
TANG, J.; WANG, L. \& YAO, Z. Analyses of urban landscape dynamics using multi-temporal satellite images: A comparison of two petroleum-oriented cities. Landscape and Urban Planning, 2008, Vol. 87, $\mathrm{N}^{\circ} 4$, p. 269-278.

VALERA LOZANO, A.; AÑÓ VIDAL, C. y SÁNCHEZ DÍAZ, J. Crecimiento urbano (1956-1998) en el entorno metropolitano de Alacant-Elx (comunidad valenciana). Boletín de la Asociación de Geógrafos Españoles, 2007, Vol. 44, № 2, p. 169-186.

VERÓN, E.M. y MERLOTTO, A. Urbanizaciones cerradas en la ciudad. Intereses y conflictos en Mar del Plata, Argentina. Revista Geográfica, 2009, № 146, p. 19-35.

VILLAR, M.C. Travesías temporales e imágenes dominantes del litoral marítimo argentino. La Plata: Anales 2001, LINTA-CIC, 2002.

VILLAR, M.C.; BOCERO, S.; MORRELL, P.; CÓCCARO, J.M.; SALCICCIA, D. y PIVETTA, R. Mar Chiquita: un partido con ámbitos desarticulados. Actas Primeras Jornadas Platenses de Geografía, 1993, p. 357-364.

WARD, D.; PHINN, S.R. \& MURRAY, A.T. Monitoring growth in rapidly urbanizing areas using remotely sensed data. Professional Geographer, 2000, Vol. 52, № 3, p. 371-386.

WEBER, C. \& PUISSANT, A. Urbanization pressure and modeling of urban growth: example of the Tunis Metropolitan Area. Remote Sensing of Environment, 2003, № 86, p. 341-352.

XIE, Z.; XU, X. \& YAN, L. Analyzing qualitative and quantitative changes in coastal wetland associated to the effects of natural and anthropogenic factors in a part of Tianjin, China. Estuarine, Coastal and Shelf Science, 2010, Vol. 86, № 3, p. 379-386. 